Iğdır Üniversitesi Fen Bilimleri Enstitüsü Dergisi, 11(3): 1866-1873, 2021

Journal of the Institute of Science and Technology, 11(3): 1866-1873, 2021

Çevre Mühendisliği / Environmental Engineering

ISSN: 2146-0574, eISSN: 2536-4618

Araştırma Makalesi / Research Article

Geliş tarihi / Received: 06-04-2021

Kabul tarihi / Accepted: 01-06-2021

To Cite: Kaplan-Bekaroglu S.S, Ates N, Kitis M, 2021. Removal of Natural Organic Matter by Steel Slag through Adsorption and Catalytic Oxidation. Journal of the Institute of Science and Technology, 11(3): 1866-1873.

\title{
Removal of Natural Organic Matter by Steel Slag through Adsorption and Catalytic Oxidation
}

\section{Sehnaz Sule KAPLAN BEKAROGLU ${ }^{1 *}$, Nuray ATES ${ }^{2}$, Mehmet KİTIS ${ }^{1}$}

\begin{abstract}
There is growing interest in reclaiming waste materials from industries such as metallurgical slags, fly ash and agricultural wastes in a resource-limited world. A large amount of steel slag is produced as waste material from steel industries. This study focused on natural organic matter (NOM) removal using steel slag as a low-cost adsorbent/catalyst. The aim of this study was to investigate the potential use of steel slag to remove NOM in waters with high specific UV absorbance $\left(\mathrm{SUVA}_{254}\right)$ value. The effects of steel slag particles size and dosages of slag and hydrogen peroxide on NOM removals were determined. UV absorbing NOM fractions were preferentially removed by the steel slag. Maximum UV absorbance and dissolved organic carbon (DOC) reduction after adsorption were $83 \%$ and $54 \%$, respectively. In addition to adsorptive properties, iron oxides on steel slag surfaces significantly catalyses hydrogen peroxide decomposition. As a result of formation of strong oxidants after hydrogen peroxide decomposition, NOM removal increased. The results showed that steel slag can be used as adsorbent and catalyst for removal of NOM in high SUVA value waters. Besides, steel slag may be effective for controlling the formation of disinfection by-products (DBPs) in drinking water treatment due to the removal of NOM fractions with high UV absorbance values.
\end{abstract}

Keywords: Adsorption, Catalytic oxidation, Natural organic matter, Steel slag

\footnotetext{
${ }^{1}$ Sehnaz Sule Kaplan-Bekaroglu (Orcid ID: 0000-0001-6826-9768), Mehmet Kitis (Orcid ID: 0000-0001-6826-9768), Department of Environmental Engineering, Faculty of Engineering, Suleyman Demirel University, Isparta, Turkey

${ }^{2}$ Nuray Ates (Orcid ID: 0000-0001-6826-9768), Department of Environmental Engineering, Faculty of Engineering, Erciyes University, Kayseri, Turkey

*Sorumlu Yazar/Corresponding Author: Sehnaz Sule Kaplan-Bekaroglu, e-mail: sulebekaroglu@sdu.edu.tr

19-21 Kasım 2020 tarihlerinde Kayseri'de (Türkiye) düzenlenen "International Conference on Energy, Environment and Storage of Energy (ICEESEN 2020)” konferansında sözlü olarak sunulmuştur.
} 


\section{INTRODUCTION}

Natural organic matter (NOM) is a complex mixture of organic compounds with varying molecular size and properties. NOM has been shown to cause some challenges during drinking water treatment such as fouling on membrane surfaces, enhancing bacterial regrowth in distribution systems, etc. Also, disinfection by products (DBPs) are unintentionally formed when a disinfectant reacts with NOM and/or bromide/iodide (Richardson et al., 2007). DBPs formation is critical issue due to their carcinogenic, cytotoxic, genotoxic, and teratogenic risks (Escobar-Hoyos et al., 2013). The DBPs standards have become stricter to reduce the impacts of DBPs in public health. A significant amount of research has been conducted on the control of DBPs formation due to the pressure of DBPs standards. Three general approaches are commonly used to control DBPs formation: 1) remove DBPs precursors, 2) reduce the amount of disinfectant and/or change the point of application, and 3) switch disinfectants. Alternative disinfectants have been reported to form lower level of halogenated DBPs but they may produce emerging DBPs (e.g., nitrosamines) which are more genotoxic than halogenated DBPs (Nawrocki and Andrzejewski, 2011). The most effective approach for controlling DBPs is to remove DBP precursors (i.e., NOM) before disinfection.

Adsorption and catalytic oxidation methods have gained attention because of their potential advantages such as high capacity, ease of operation, and cost effectiveness. Iron oxide particles may be effective adsorbents and heterogeneous catalysts for the removal of synthetic organics and NOM from waters (Kitis and Kaplan, 2007; Shuai and Zinati, 2009; Tozum-Akgul and Yigit, 2017). Our previous studies showed that pumice particles, which were coated with iron oxide were effective for NOM removal through adsorption and catalytic oxidation in various water sources to overcome settling and sludge problem of fine iron oxide particles (Kitis and Kaplan, 2007; Shuai and Zinati, 2009; KaplanBekaroglu et al., 2010; Tozum-Akgul and Yigit, 2017). Therefore, in this study, we hypothesized that iron oxide containing waste materials, such as steel slag, can also be effective adsorbent and/or catalyst for NOM removal. In this context, the main objectives of this study were: (1) to investigate the potential use of steel slag to remove NOM through adsorption only; and (2) to investigate the effectiveness of combined adsorption and catalytic oxidation by hydrogen peroxide addition for NOM removal. Steel slag, mainly consisting of iron oxides and calcium oxides, is a by-product of steel manufacturing processes (Tozum-Akgul and Yigit, 2017). More than 400 million tonnes of iron and steel slags are produced globally in 2017 (Branca et al., 2020). Steel slag particles have been tested in environmental applications for the removal of dyes, metals, and organic compounds using either batch or fixed-bed scenarios (Ramakrishna and Viraraghavan, 1998; Dimitrova, 2002; Oh et al.,2012). Studies reported that steel slag could be used as an adsorbent and/or catalyst for removing contaminants with a high removal efficiency with a low possibility of secondary contamination. It was generally found that most of the toxic elements was released barely leached from steel slag after extended periods of mixing (Oh et al.,2012). Study by Tozum-Akgul and Yigit, (2017) evaluated NOM removal efficiency of steel slag used both as the catalyst and as the adsorbent for low SUVA natural water and synthetic humic acid (HA) solution) (Tozum-Akgul and Yigit, 2017). More research with real waters with high SUVA values is needed to evaluate the potential of steel slag as a practical and potentially more sustainable in water treatment process.

\section{MATERIALS AND METHODS}

Steel slag samples (obtained from the Eregli Iron and Steel Production Plant, Turkey) were divided into different particle size fractions with sieving (<180, 180-300, 300-500, 500-710, 710-1000, and $1000-1180 \mu \mathrm{m})$ after grinding. Distilled and deionized water was used to wash steel slag samples. Steel 
slag samples washed until the conductivity level was less than $10 \mu \mathrm{S} \mathrm{cm}^{-1}$ in the washing solution. After washing, the particle fractions were dried constant weight was achieved at $80^{\circ} \mathrm{C}$. All fractions were kept at a desiccator until use. Physicochemical characteristic of each steel slag fraction was shown in Table 1. A pH equilibration method was used to determine point of zero charge ( $\mathrm{pH}_{\mathrm{PZC}}$ ) values of steel slag samples (Dastgheib et al., 2004). Brunauer-Emmett-Teller (BET) method with using Micrometrics Gemini V analyser was used for specific surface measurements. Spectro IQ-II analyser was used for XRF analysis. Steel slag particles exhibited basic character and the $\mathrm{pH}_{\mathrm{PZC}}$ values of particles ranged between 11.61-12.03. Steel slag fractions had small surface areas, ranging between 0.1 and $3.1 \mathrm{~m}^{2} \mathrm{~g}^{-1}$. Studies reported that steel slags have a typically low specific surface area of less than $10 \mathrm{~m}^{2} \mathrm{~g}^{-1}$ (Manchisi et al., 2020). The chemical compositions of steel slags studied by several researchers, and they found that steel slags consist primarily of $\mathrm{CaO}, \mathrm{Fe}_{2} \mathrm{O}_{3}, \mathrm{SiO}_{2}, \mathrm{MgO}$, and $\mathrm{Al}_{2} \mathrm{O}_{3}$ (Yigit and Tozum, 2012). Acid digestion analysis was used to determine iron contents of the adsorbent samples (Tozum-Akgul and Yigit, 2017). Iron contents of steel slag were $23.2 \mathrm{mg} \mathrm{g}^{-1}$ according to acid digestion analysis. XRF data has also show that steel slag particles contained significant amounts of $\mathrm{Fe}_{2} \mathrm{O}$ (about 27\%).

Table 1. Physicochemical characteristics of the steel slag particles

\begin{tabular}{lcc}
\hline Steel Slags & BET surface area $\left(\mathbf{m}^{\mathbf{2}} \mathbf{g}^{\mathbf{- 1}}\right)$ & pHPZC \\
\hline SS1 $(<180 \mu \mathrm{m})$ & 3.1 & 12.07 \\
SS2 $(180-300 \mu \mathrm{m})$ & 2.1 & 12.03 \\
SS3 $(300-500 \mu \mathrm{m})$ & 1.4 & 11.96 \\
SS4 $(500-710 \mu \mathrm{m})$ & 1.2 & 11.77 \\
SS5 $(710-1000 \mu \mathrm{m})$ & 1.1 & 11.64 \\
SS6 $(1000-1180 \mu \mathrm{m})$ & 1.0 & 11.61 \\
\hline
\end{tabular}

*Codes of $1,2,3,4,5$, and 6 represent steel slag particle size fractions of $<180 \mu \mathrm{m}, 180-300 \mu \mathrm{m}, 300-500 \mu \mathrm{m}$, 500-710 $\mu \mathrm{m}, 710-1000 \mu \mathrm{m}$, and 1000-1180 $\mu \mathrm{m}$, respectively).

Influent of drinking water treatment plant in Myrtle Beach (MB) was selected for NOM source. The MB drinking water treatment plants is located in South Carolina (SC), USA. A reverse osmosis (RO) membrane system was used to concentrate NOM in this raw water. DOC concentration was 4.47 $\mathrm{mg} \mathrm{L}^{-1}$ for all experiments. SUVA 254 value of diluted MB water was $4.43 \mathrm{~L} \mathrm{mg}^{-1} \mathrm{~m}^{-1}$. SUVA 254 represents the aromatic character of organic of the organic matter. High SUVA values showed that MB water has higher degree of aromaticity. The hydrophobic fractions of NOM, mostly in humic and highly aromatic character, have been found to significantly contribute to DBPs formation (Kitis et al., 2004). The measured physicochemical characteristics of diluted MB water are as follows; conductivity: $48 \mu \mathrm{Scm}^{-1}$, alkalinity: $32 \mathrm{mg} \mathrm{L}^{-1}$, pH: 7.54 .

Experiments were conducted in two phases: 1) batch adsorption isotherms in which steel slag was tested as adsorbent, 2) batch tests in which both steel slag and hydrogen peroxide was dosed to investigate combined adsorption and catalytic oxidation. Completely mixed batch reactors used for all experiments. Kinetic experiments were initially performed to determine equilibrium time. According to the results of kinetic experiments, $20 \mathrm{~h}$ of mixing was selected for all experiments. For batch adsorption isotherm tests, the adsorbent dosages in the isotherms were 30, 100, 500, 1000, 3000, 6000, and 10000 mg L ${ }^{-1}$ with employing constant adsorbate concentration. Various steel slag and hydrogen peroxide dosages were tested for combined adsorption and catalytic oxidation experiments were. After dosing slag or slag/peroxide, samples were kept in a temperature-controlled orbital shaker with well mixing at constant temperature $\left(20 \pm 1^{\circ} \mathrm{C}\right.$ ). All experiments were conducted at $\mathrm{pH} 7.54$ (raw water $\mathrm{pH}$ ) without buffer addition. After an equilibrium time of $20 \mathrm{~h}$, slag particles in each bottle were separated through 
filtration using a pre-washed $0.45-\mu \mathrm{m}$ membrane filter to prevent organic material leak (KaplanBekaroglu et al., 2010). After filtrating, both $\mathrm{UV}_{254}$ absorbance and DOC were measured. TOC analyzer (TOC-VCPH, Shimadzu) according to SM 5310 B was used for measuring of DOC concentrations. A UV-visible spectrophotometer (Beckman DU-640) was used for the UV absorbance measurements in water samples. After $20 \mathrm{~h}$, residual peroxide was measured and was quenched by sodium sulfite $\left(\mathrm{Na}_{2} \mathrm{SO}_{3}\right)$ in catalytic oxidation experiments. Titrimetric test kit (HYP-1, Hach-Lange) was used to measure hydrogen peroxide concentration. Reagent grade chemicals were used throughout the work.

\section{RESULTS AND DISCUSSION}

\section{Adsorption of NOM}

After the initial kinetic tests, a serious of batch experiments were conducted to investigate adsorptive NOM removal of steel slag particles. The reductions in $\mathrm{UV}_{254}$ absorbance by different particle size fractions and slag dosages are shown in Figure 1. In general, the smallest size fraction $(<180 \mu \mathrm{m})$ of steel slag exhibited the highest UV absorbance reduction. When the dosages of steel slag particles increased UV absorbance and DOC removals increased. Maximum UV absorbance reduction was $83 \%$. The lowest UV absorbance reduction was found in the largest particle size fraction. These results cannot be explained with highest surface area of smallest size fraction due to low and narrow ranged surface areas (1.0-3.1 $\left.\mathrm{m}^{2} \mathrm{~g}^{-1}\right)$. Detailed analysis with surface chemistry and morphology of steel slag particle size fractions should be performed to evaluate differences on removal. DOC removal trend was similar to UV absorbance and maximum DOC reduction for the smallest size fraction $(<180 \mu \mathrm{m})$ of steel slag was 54\% at $10000 \mathrm{mg} \mathrm{L}^{-1}$ steel slag dose. Lower UV absorbance and DOC reductions was reported in natural waters with low SUVA value waters (Tozum-Akgul and Yigit, 2017).

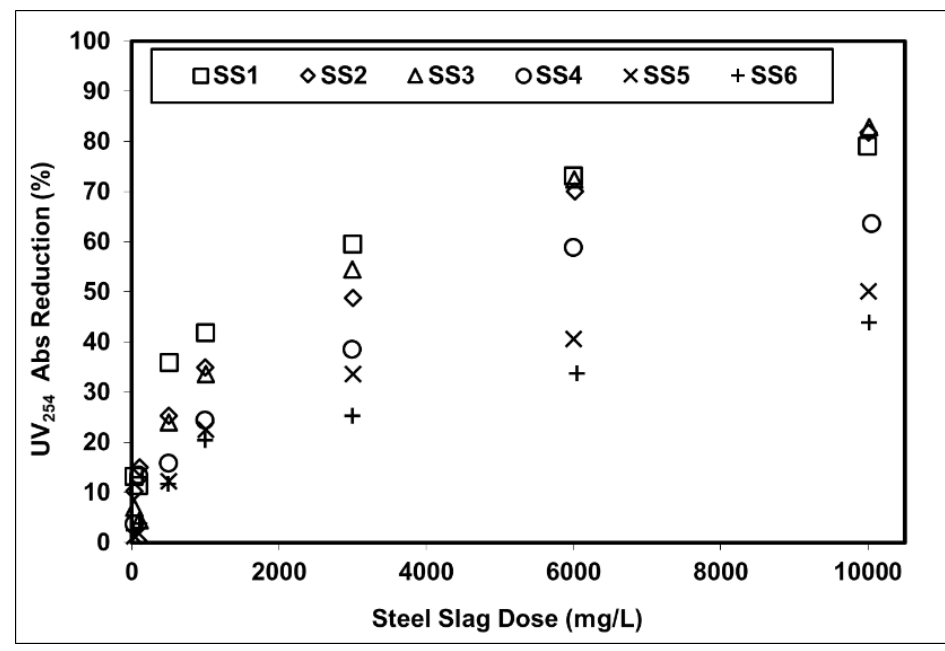

Figure 1. $\mathrm{UV}_{254}$ absorbance reductions obtained by steel slag samples (adsorption only) (Codes of $1,2,3,4,5$ and 6 in the legend present steel slag particle size fractions of $<180,180-300,300-500,500$ $710,710-1000$ and $1000-1180 \mu \mathrm{m}$ respectively).

SUVA values after adsorption were lower compared to before adsorption. SUVA 254 value was decreased a result of adsorption and maximum SUVA $_{254}$ reduction is $54 \%$ in the smallest size fraction. These results showed that adsorbed NOM species had relatively higher degrees of aromaticity. Samples with a high $\mathrm{SUVA}_{254}$ value (ie., $\geq 4 \mathrm{~L} \mathrm{mg}^{-1} \mathrm{~m}^{-1}$ ) have a relatively high content of hydrophobic organic compounds and indicates hydrophobic nature of NOM. Due to strong correlations between SUVA 254 values and DBP formation, decreasing $\mathrm{SUVA}_{254}$ values means decreasing of DBPs formation. 
Adsorption isotherm results by steel slag are shown in Figure 2. Adsorption capacities of steel slag samples ranged between $0.19-1.94 \mathrm{mg} \mathrm{g}^{-1} \cdot \mathrm{pH}$ values were increased after adsorption and $\mathrm{pH}$ values were around 11-12 after adsorption. Besides $\mathrm{pH}$ values, alkalinity and conductivity of water were increased after adsorption. Increasing in $\mathrm{pH}$ values, alkalinity and conductivity can be explained by dissolution of $\mathrm{CaO}$ which is used as addition agent in steel making processes (Oh et al., 2012).

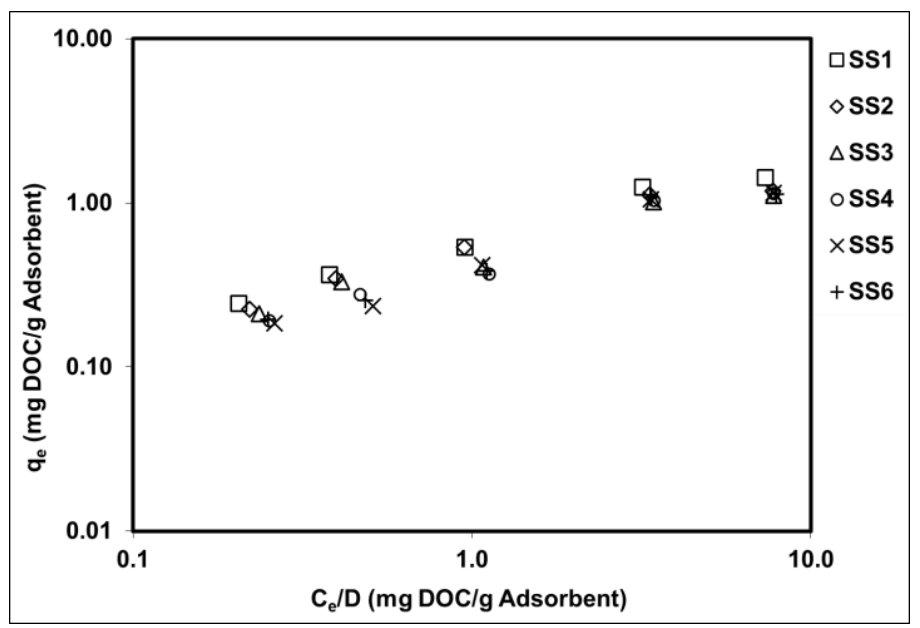

Figure 2. Adsorption capacities of MB water by steel slag particles. (Codes of 1,2,3,4,5, and 6 in the legend present steel slag particle size fractions of <180, 180-300, 300-500, 500-710, 710-1000, and 1000-1180 $\mu \mathrm{m}$, respectively).

\section{Catalytic Oxidation of NOM}

Addition to the adsorbent properties, iron oxide on steel slag particles can be effective on formation strong oxidants as a result of catalysing the decomposition of hydrogen peroxide. To prove catalytic effective of steel slag particles, firstly, we tested removal of NOM by only hydrogen peroxide oxidation. $\mathrm{UV}_{254}$ absorbance reductions by only peroxide oxidation were less than $5 \%$ for steel slag samples. The results showed that hydrogen peroxide alone is not sufficient to oxide NOM. For smallest size fraction of steel slag particles, $60 \% \mathrm{UV}_{254}$ absorbance was obtained at $3000 \mathrm{mg} \mathrm{L}^{-1}$ dose (without peroxide). After adding hydrogen peroxide $\left(1000 \mathrm{mg} \mathrm{L}^{-1}\right)$ at the $3000 \mathrm{mg} \mathrm{L}^{-1}$ steel slag dose, $\mathrm{UV}_{254}$ absorbance was obtained $77 \%$ (Figure 3 ). These results proved that iron oxide in steel slag surfaces catalysed hydrogen peroxide decomposition to form strong oxidants, probably hydroxyl radicals. Similar to UV removal, DOC removal is increased from $36 \%$ to $51 \%$. Increased NOM removals were found for iron oxide coated pumice when dosed with peroxide in our previous publication (Kitis and Kaplan, 2007). In general, NOM decrease more when measured as $\mathrm{UV}_{254}$ than as DOC in various advanced oxidation processes studied, e.g. during $\mathrm{UV} / \mathrm{H}_{2} \mathrm{O}_{2}$ (Moncayo-Lasso et al, 2008), $\mathrm{TiO}_{2} / \mathrm{UV}$ (Liu et al., 2010), catalytic oxidation (Kitis and Kaplan, 2007), and Fenton processes (Nie et al.,2010). The high removal of $U_{254}$ values shows that NOM macro-molecules with high UV absorbance are broken down into lower molecular weight by-products with lower UV absorbance.

Figure 4 shows the $\mathrm{UV}_{254}$ absorbance reductions achieved for all steel slag fractions by different peroxide dosages and $3000 \mathrm{mg} \mathrm{L}^{-1}$ steel slag dose. Smallest particle size fractions $(<180 \mu \mathrm{m})$ had highest NOM removal. Both $\mathrm{UV}_{254}$ absorbance and DOC reductions decreased with increasing particle size fractions. At $3000 \mathrm{mg} \mathrm{L}^{-1}$ steel slag and $1000 \mathrm{mg} \mathrm{L}^{-1}$ hydrogen peroxide dosages, $\mathrm{UV}_{254}$ absorbance and DOC reductions of the smallest particle size fractions were $77 \%$ and $\% 51$, respectively. At constant steel slag dose, reductions of $\mathrm{UV}_{254}$ absorbance increased with increasing peroxide dose. Increasing NOM removal with increasing hydrogen peroxide dose provided direct evidence of strong oxidants formation 
as a result of decomposition of hydrogen peroxide iron oxide surfaces. Overall, NOM removal by steel slag and hydrogen peroxide is provided both by adsorption and catalytic oxidation.

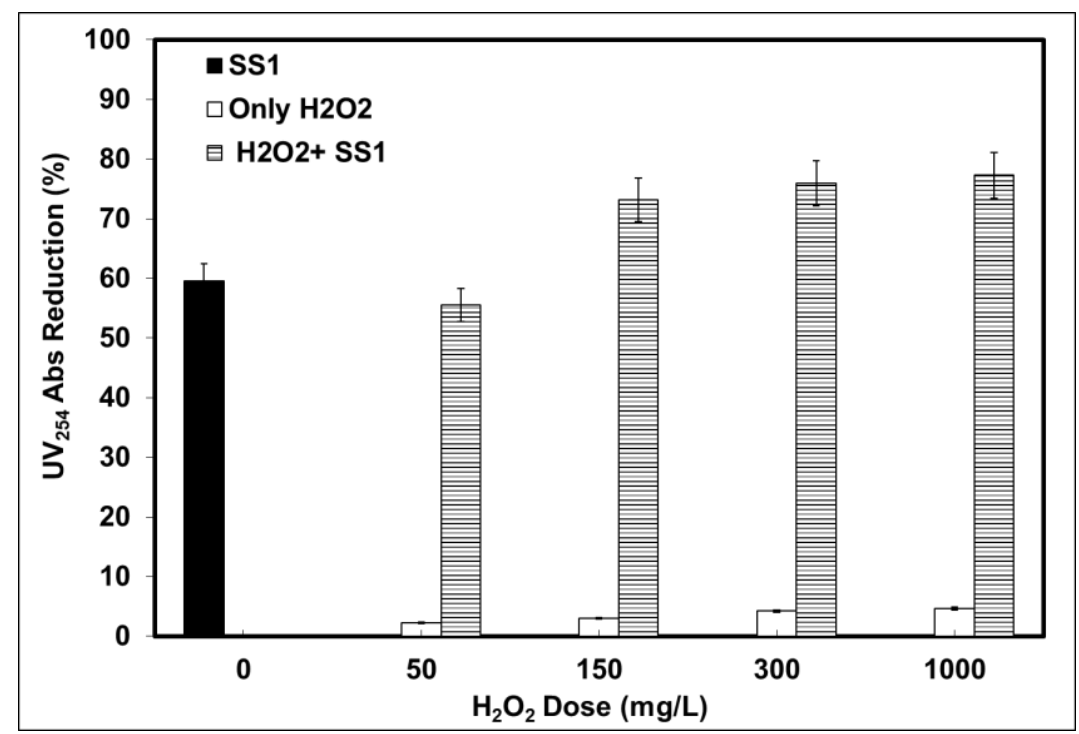

Figure 3. UV absorbance reductions by steel slag in adsorption only, hydrogen peroxide alone, and steel slag and peroxide together (SS1 presents steel slag particle size fractions of $<180 \mu \mathrm{m}$, steel slag dose $=3000 \mathrm{mg} \mathrm{L}^{-1}$, reaction time $=20 \mathrm{~h}$ ). Error bars show the $95 \%$ confidence intervals.

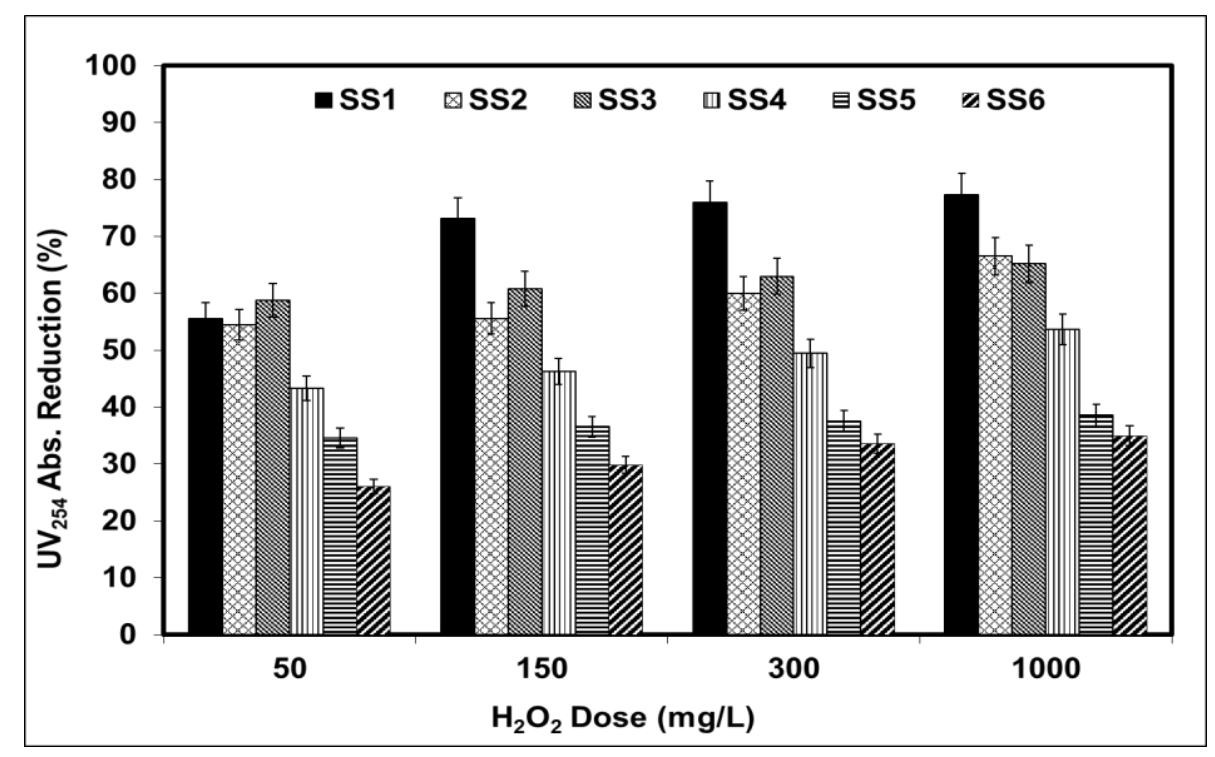

Figure 4. $\mathrm{UV}_{254}$ absorbance reductions obtained by steel slag particles (Codes of 1,2,3,4,5 and 6 in the legend present steel slag particle size fractions of <180, 180-300, 300-500, 500-710, 710-1000 and 1000-1180 $\mu \mathrm{m}$ respectively, steel slag dose $=3000 \mathrm{mg} \mathrm{L}^{-1}$, reaction time $=20 \mathrm{~h}$ ). Error bars show the $95 \%$ confidence intervals.

Increasing of ratio of $\mathrm{H}_{2} \mathrm{O}_{2} / \mathrm{steel}$ slag dosage $(\mathrm{mg} / \mathrm{mg}$ ) increased NOM removals (Figure 5). About $42 \%$ DOC reductions were obtained for smallest size fraction when the ratio of $\mathrm{H}_{2} \mathrm{O}_{2}$ /steel slag dose ratio was 0.02 (3000 $\mathrm{mg} \mathrm{L}^{-1}$ steel slag and $50 \mathrm{mg} \mathrm{L}^{-1} \mathrm{H}_{2} \mathrm{O}_{2}$ ). When ratio increased from 0.02 to 0.33 (1000 $\mathrm{mg} \mathrm{L}^{-1} \mathrm{H}_{2} \mathrm{O}_{2}$ and $3000 \mathrm{mg} \mathrm{L}^{-1}$ steel slag), DOC removal increased \%51. Similar to DOC, UV absorbance reduction increased from $\% 56$ to $\% 77$ when ratio increased from 0.02 to 0.33 . At constant steel slag dose, reductions on $\mathrm{UV}_{254}$ absorbance increased with increasing hydrogen peroxide dose. Similarly, at constant hydrogen peroxide dose, $\mathrm{UV}_{254}$ absorbance reductions increased with increasing steel slag dose. Increasing NOM removal with increasing peroxide dose provided direct experimental 
evidence that iron oxide surfaces can catalyse decomposition of hydrogen peroxide to form strong oxidants. Overall, the results showed that removal of NOM by steel slag and hydrogen peroxide is provided both by adsorption and catalytic oxidation. Steel slag can be used as low-cost and sustainable adsorbent/catalysts for NOM removal in high-SUVA waters. Many solid waste sources contain metals or metal oxides can be reused as catalysts. However, choosing waste material is critical due to secondary contamination as a result of leaching. Oh et al. (2012) reported that toxic elements were barely leached from steel slag according to results of leaching tests (Oh et al., 2012).

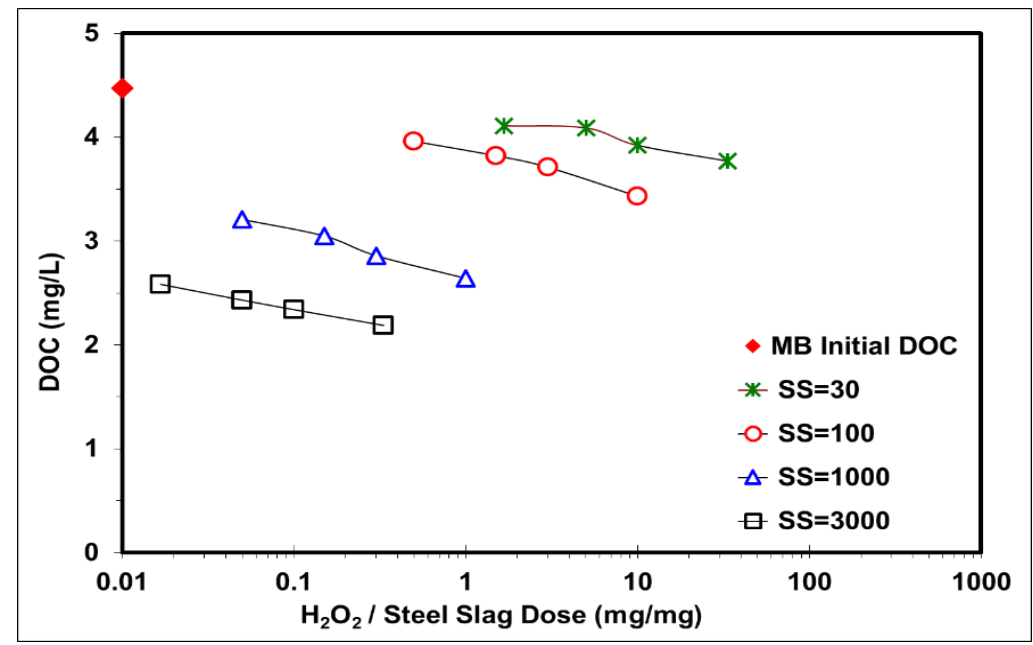

Figure 5. The effects of $\mathrm{H}_{2} \mathrm{O}_{2} /$ steel slag dose ratio on DOC removals for $<180 \mu \mathrm{m}$ steel slag particles (steel slag dosages are in $\mathrm{mg} \mathrm{L}^{-1}$ in the legend).

\section{CONCLUSION}

Studies on recycling processes for waste materials have been attracting much attention because of economic and environmental considerations. Steel slag, by product of steel industry, was tested for the adsorptive and oxidative removal of NOM. According to best literature knowledge of the authors, steel slag has not been tested yet for NOM removal for high-SUVA waters. Maximum UV absorbance and DOC reduction after adsorption for the smallest size fraction $(<180 \mu \mathrm{m})$ of steel slag were $83 \%$ and $54 \%$, respectively. Decreases in $\mathrm{SUVA}_{254}$ values after adsorption showed that that the adsorbed DOM species had relatively higher degrees of aromaticity. Addition to adsorptive properties, iron oxide in steel slag surfaces also catalysed the decomposition of hydrogen peroxide to form strong oxidants and enhanced NOM removal. At a steel slag dosage of $3000 \mathrm{mg} \mathrm{L}^{-1}$, maximum removal of DOC in adsorption experiments without hydrogen peroxide was $36 \%$ for the smallest size fraction of steel slag. When hydrogen peroxide and steel slag particles were dosed together, DOC removal obtained were $51 \%$, respectively, employing $1000 \mathrm{mg} \mathrm{L}^{-1}$ hydrogen peroxide and $3000 \mathrm{mg} \mathrm{L}^{-1}$ steel slag dosages. The results show that steel slag is promising adsorbent and heterogeneous catalyst for NOM removal and DBPs formation control due to iron oxide content. However, further pilot-scale testing is necessary to verify these lab-scale findings and to determine the practical application aspects of the process.

\section{ACKNOWLEDGEMENTS}

We would like to thank Professor Tanju Karanfil and his research group at Clemson University, USA for all of their contributions to this work.

\section{Conflict of Interest}

The article authors declare that there is no conflict of interest between them. 


\section{Author's Contributions}

The authors declare that they have contributed equally to the article.

\section{REFERENCES}

Branca TA, Colla V, Algermissen D, Granbom H, Martini U, Morillon A, Pietruck R, Rosendahl S, 2020. Reuse and Recycling of By-Products in the Steel Sector: Recent Achievements Paving the Way to Circular Economy and Industrial Symbiosis in Europe. Metals, 10 (3):345.

Dastgheib SA, Karanfil T, Cheng W, 2004. Tailoring Activated Carbons for Enhanced Removal of Natural Organic Matter from Natural Waters. Carbon, 42 (3):547-557.

Dimitrova SV, 2002. Use of Granular Slag Columns for Lead Removal. Water Research, 36 (16):4001-4008.

Escobar-Hoyos LF, Hoyos-Giraldo LS, Londoño-Velasco E, Reyes-Carvajal I, Saavedra-Trujillo D, CarvajalVarona S, Sánchez-Gómez A, Wagner ED, Plewa MJ, 2013. Genotoxic and Clastogenic Effects of Monohaloacetic Acid Drinking Water Disinfection By-Products in Primary Human Lymphocytes. Water Research, 47(10):3282-3290.

Kitis M, Kaplan SS, 2007. Advanced Oxidation of Natural Organic Matter Using Hydrogen Peroxide and IronCoated Pumice Particles. Chemosphere, 68 (10):1846-1853.

Kitis M, Karanfil T, Kilduff JE, 2004. The Reactivity of Dissolved Organic Matter for Disinfection By-Product Formation. Turkish Journal of Engineering and Environmental Sciences, 28 (3):167-180.

Liu S, Lim M, Fabris R, Chow C, Drikas M, Amal R, 2010. Comparison of Photocatalytic Degradation of Natural Organic Matter in Two Australian Surface Waters Using Multiple Analytical Techniques. Organic Geochemistry, 41 (2):124-129.

Manchisi J, Matinde E, Rowson NA, Simmons MJ, Simate GS, Ndlovu S, Mwewa B, 2020. Ironmaking and Steelmaking Slags As Sustainable Adsorbents for Industrial Effluents and Wastewater Treatment: A Critical Review of Properties, Performance, Challenges and Opportunities. Sustainability, 12 (5):2118.

Moncayo-Lasso A, Pulgarin C, Benítez N, 2008. Degradation of DBPs' Precursors in River Water Before and After Slow sand Filtration by Photo-Fenton Process at pH 5 in a Solar CPC Reactor. Water Research, 42 (15):4125-4132.

Nawrocki J, Andrzejewski P, 2011. Nitrosamines and Water. Journal of Hazardous Materials, 189 (1-2):1-8.

Nie Y, Hu C, Zhou L, Qu J, Wei Q, Wang D, 2010. Degradation characteristics of humic acid over iron oxides/Fe0 core-shell nanoparticles with UVA/ $\mathrm{H}_{2} \mathrm{O}_{2}$. Journal of Hazardous Materials, 173 (1-3):474-479.

Oh C, Rhee S, Oh M, Park J, 2012. Removal Characteristics of As (III) and As (V) from Acidic Aqueous Solution By Steel Making Slag. Journal of Hazardous Materials, 213:147-155.

Ramakrishna KR, Viraraghavan T,1998. Use of Slag for Dye Removal. Waste Management, 17(8):483-488.

Richardson SD, Plewa MJ, Wagner ED, Schoeny R, DeMarini DM, 2007. Occurrence, Genotoxicity, and Carcinogenicity of Regulated and Emerging Disinfection By-Products in Drinking Water: A Review and Roadmap for Research. Mutation Research/Reviews in Mutation Research, 636 (1-3):178-242.

Shuai X, Zinati G, 2009. Proton Charge and Adsorption of Humic Acid and Phosphate on Goethite. Soil Science Society of America Journal, 73 (6):2013-2020.

Tozum-Akgul S, Yigit NO, 2017. Natural Organic Matter Removal by Catalytic Ozonation using Original and Surface-Modified Waste and Natural Materials. Desalination and Water Treatment, 67:117-124.

Yigit NO, Tozum S, 2012. Removal of Selenium Species from Waters Using Various Surface-Modified Natural Particles and Waste Materials. Clean-Soil, Air, Water, 40 (7):735-745. 